\title{
ENSINANDO INGLÊS COM CORPORA PARA PROFISSIONAIS DA ÁREA DE PUBLICIDADE
}

Resumo: Este artigo teve como objetivo principal apresentar uma atividade de ensino de Inglês como Língua Estrangeira com corpora para estudantes do idioma que atuam na área de Publicidade. Para tanto, encontramos suporte teórico principal na Linguística de Corpus, uma área que proporciona a pesquisa, o estudo e a exploração da língua em uso (BERBER SARDINHA, 2004; 2009; 2011). Particularmente, na sua vertente que trata da interface corpus e ensino de Língua Estrangeira, com base em abordagens desenvolvidas por Sinclair (1991; 2004a; 2004b), Johns (1991), Willis (1990) e Berber Sardinha (2009; 2011), que dizem respeito à exploração de corpora no ensino por meio da identificação e da análise de padrões lexicogramaticais da língua e ao ensino por meio da abordagem lexical. Os resultados da análise do corpus sugerem que existe uma grande variedade de padrões de linguagem relativos a Publicidade a serem estudados. Encontramos diversos padrões e colocados que, se bem explorados por professores e alunos, podem auxiliar na comunicação dos profissionais dessa área. Propomos, assim, uma atividade de ensino de Língua Inglesa com alguns desses padrões. Nossa pesquisa, bem como este artigo, pretende contribuir para o desenvolvimento de atividades de ensino baseadas em corpora, bem como para estudantes que atuam na área de Publicidade, para a qual existe pouco material didático no mercado.

Palavras-chave: Linguística de Corpus; Ensino de Língua Inglesa como Língua Estrangeira.

Abstract: This paper aimed at presenting an activity for the teaching of English as a foreign language with corpora to students who work in Advertising. In order to achieve this objective, the main theoretical framework for the research is provided by Corpus Linguistics, which is an area that supports the research and the study of the language in use (BERBER SARDINHA, 2004; 2009, 2011). Particularly, this study is mainly concerned with the interface between corpus and the teaching of foreign languages, based on the approaches developed by Sinclair (1991; 2004a; 2004b), Johns (1991), Willis (1990) and Berber Sardinha 
(2009; 2011), which refer to the exploration of corpora in language teaching through the identification and analysis of lexicogramatical patterns and the teaching based on a lexical approach. The results of the analysis of the corpus showed that there is a great variety of language patterns related to Advertising to be studied. We have found a range of patterns and collocates which, if adequately explored by both teachers and students, can help the professionals in this field to communicate effectively. We propose, then, an activity for the teaching of English with some of those patterns. Both the study and the present paper intend to contribute to the development of classroom activities based on corpora, as well as to professionals in Advertising, for whom there is few teaching materials available.

Keywords: Corpus Linguistics; Teaching of English as a Foreign Language.

\section{INTRODUÇÃO}

O ensino de Línguas Estrangeiras para profissionais de áreas específicas é um desafio, pois existe pouco material disponível no mercado que atenda às necessidades dos alunos de comunicar-se em seu meio profissional. A minha experiência profissional, como professora de Inglês como Língua Estrangeira, em aulas particulares e em empresas, especialmente em agências de Publicidade, levou-me a observar que esse contexto de ensino requer um conteúdo e um material adequado às necessidades dos alunos de utilizarem o idioma em seu meio profissional. Em nossa experiência, pudemos verificar que os alunos normalmente conhecem os termos usados em sua área de atuação, porém apresentam dificuldades no uso desse vocabulário específico. É por meio de materiais autênticos ${ }^{1}$, como textos

1 Consideramos material autêntico o que não foi produzido ou criado para fins pedagógicos. 
e vídeos, que os alunos podem ter contato com essa língua em uso; observamos que os materiais didáticos disponíveis no mercado proporcionam muito pouco contato com esse tipo de material, bem como com o vocabulário utilizado em seu meio profissional.

Diante desse panorama e de nosso contexto de ensino de Inglês como Língua Estrangeira, doravante ILE, em agências de Publicidade, desenvolvemos uma pesquisa ${ }^{2}$ para a criação de atividades de ensino específicas, a qual descrevemos neste artigo, a fim de que professores que lecionam em contextos semelhantes possam aproveitar-se desta metodologia para criar suas próprias atividades.

Em síntese, nossa pesquisa consistiu em dois objetivos principais: o de extrair e analisar o uso de alguns dos padrões lexicogramaticais ${ }^{3}$ mais frequentes no meio publicitário e, em seguida, o de utilizar esses padrões na preparação de atividades ${ }^{4}$ de ensino.

Para atingir os objetivos propostos, desenvolvemos a seguinte metodologia de pesquisa: (1) coleta de um corpus ${ }^{5}$

2 Pesquisa em nível de Mestrado desenvolvida pela autora de 2009 a 2012 pela PUC-SP com auxílio bolsa Capes.

3 Entendemos por padrão lexicogramatical a combinação de duas ou mais palavras que ocorre com frequência com um significado associado a ela (BERBER SARDINHA, 2004).

4 Entendemos atividade como "uma sequência de trabalhos feitos pelos alunos na sala de aula, individualmente ou não, veiculados em um material de ensino" (BERBER SARDINHA, 2011, p. 307).

5 Corpus refere-se à coletânea de textos em formato eletrônico coletados de forma criteriosa 
de mais de 1 milhão de palavras composto por artigos escritos e transcrição de vídeos com textos lidos e entrevistas de uma revista digital de Publicidade, que chamamos de ad corpus; (2) análise do corpus e sua comparação com um corpus de referência, o BNC (British National Corpus) para a identificação dos padrões lexicogramaticais distintivos do corpus de estudo, por meio do programa Wordsmith Tools (SCOTT, 2008); (3) transposição dos achados para a atividade de ensino.

Encontramos suportes teórico e metodológico principais na Linguística de Corpus, doravante LC, que, dedicandose à coleta criteriosa e exploração de conjuntos de dados linguísticos textuais, denominados corpora, proporciona a pesquisa, o estudo e a exploração da língua em uso, de forma empírica e por meio do uso de computador (BERBER SARDINHA, 2004). Mais especificamente, nossa proposta fundamenta-se na área de pesquisa baseada em corpus que se preocupa com o ensino de Línguas Estrangeiras. Uma das questões principais da LC nesta área é como incorporar o estudo e a análise da língua por meio de corpora no ensinoaprendizagem de línguas.

Sinclair (1991; 2004a; 2004b) e Johns (1991) apresentam

a fim de servir para a pesquisa de uma língua ou variedade linguística (BERBER SARDINHA, 2004). O plural de corpus é corpora. 
formas de se trabalhar os conceitos e as ferramentas da LC no ensino por meio de concordâncias (ver um exemplo na Metodologia), que são "listagens de uma palavra específica (o 'nódulo', node word ou search word) juntamente com parte do texto onde ocorreu" (BERBER SARDINHA, 2009, p.9). Johns é o criador do Data Driven Learning (DDL), abordagem na qual o aluno é incentivado a estudar os padrões lexicogramaticais da língua por meio de concordâncias, desenvolvendo, assim a habilidade de um pesquisador. Cabe ao professor guiar o aluno, facilitando esse trabalho de formular hipóteses sobre a língua, buscar respostas para suas questões, identificar padrões recorrentes e fazer generalizações a respeito dos achados.

Berber Sardinha $(2009 ; 2011)$ também apresenta maneiras de se usar corpora em sala de aula propondo três tipos de atividades para o ensino de ILE, quais sejam: centradas na concordância, centradas no texto e multimídia/multigênero. As atividades centradas na concordância focam na identificação dos padrões lexicogramaticais e são sugeridos exercícios acompanhando as concordâncias, o que propomos em nossa atividade. $O$ segundo tipo de atividade parte de um texto e trabalha as questões que o envolvem, como tema, gênero, ideias principais, além de trazer concordâncias 
com palavras do texto. Da mesma maneira, propomos que os alunos usem o texto, não só concordâncias. As atividades multimídia/multigênero envolvem diferentes mídias e gêneros e incentivam o aluno a entender as diferenças entre eles e seus padrões frequentes ou típicos.

Em contato com professores de ILE em contextos diversos, bem como na área de Publicidade, observamos que são utilizados materiais autênticos, geralmente baseados em textos da Internet, de sites das áreas em que os alunos atuam. Entretanto, as atividades preparadas pelo professor, assim como a escolha dos itens a serem explorados nestes textos são comumente feitas sem acesso a recursos da LC e os alunos acabam por estudar somente itens gramaticais retirados dos textos ou então extraem o vocabulário que acreditam ser usualmente empregado sem analisar sua frequência ou o seu uso.

Pretendemos, aqui, mostrar como utilizar esses recursos, contribuindo, assim, para que o ensino de ILE possa modernizar-se e que tecnologias sejam usadas para o desenvolvimento de aulas mais significativas e customizadas às necessidades dos alunos em seu meio profissional. 


\section{LINGUÍSTICA DE CORPUS}

Este trabalho tem como fundamentação teórica principal a Linguística de Corpus que, segundo Berber Sardinha (2004, p.3), “ocupa-se da coleta e exploração de corpora, ou conjuntos de dados linguísticos textuais coletados criteriosamente, com o propósito de servirem para a pesquisa de uma língua ou variedade linguística".

Ainda segundo o autor, um corpus pode ser definido como:

um conjunto de dados linguísticos (pertencentes ao uso oral ou escrito da língua, ou a ambos), sistematizados segundo determinados critérios, suficientemente extensos em amplitude e profundidade, de maneira que sejam representativos da totalidade do uso linguístico ou de algum de seus âmbitos, dispostos de tal modo que possam ser processados por computador, com a finalidade de propiciar resultados vários e úteis para a descrição e análise. (2004, p.18)

É importante destacar que um corpus, peça-chave da pesquisa em LC, deve ser coletado para servir a um propósito específico. De acordo com Berber Sardinha (2004), alguns dos principais critérios para a formação de um corpus computadorizado são: (1) deve ser formado por textos autênticos, ou seja, não pode ter sido produzido para servir 
de objeto de pesquisa; (2) deve ter um conteúdo selecionado criteriosamente, de acordo com as características e objetivos estabelecidos pelo criador e (3) deve ser um conjunto representativo de uma variedade linguística ou de uma língua.

Firth (1957) é considerado um dos estudiosos mais importantes para a fundamentação da Linguística de Corpus, especialmente no que diz respeito ao estudo de uma língua em função do seu contexto de uso (McENERY; WILSON, 2001). Os estudos de Firth nos anos 50 contribuíram para o surgimento de uma nova tradição de linguistas, chamados neo-firthianos, como John Sinclair e Michael Halliday. No final dos anos 50, o empirismo, e consequentemente as pesquisas com corpora, perderam força com a chegada da teoria racionalista de Chomsky, que rejeitava a pesquisa com dados autênticos e criticava a confiabilidade dos corpora coletados manualmente. As pesquisas com corpora reapareceram e consolidaram-se nos anos 80 , com o advento de uma tecnologia que possibilitou a análise de grandes quantidades de dados linguísticos por meio do computador. Na década de 90, suítes de software como o Wordsmith Tools, de Mike Scott, facilitaram ainda mais o trabalho na área e atualmente existem diversos programas e ferramentas à disposição 
de linguistas de corpus, que atuam em universidades em diversos países. No Brasil, a LC vem ganhando força, com diversas publicações (livros, revistas, jornais, dissertações e teses) e encontros entre pesquisadores da área em diferentes pontos do país (Cf. BERBER SARDINHA e ALMEIDA, 2008).

A LC não faz a separação rígida entre léxico e sintaxe, ao contrário, aponta a existência de um nível do sistema linguístico conhecido por lexicogramática, que engloba o vocabulário e a gramática (BERBER SARDINHA, 2004). Um dos conceitos que justificam o estudo de padrões lexicogramaticais é o de linguagem enquanto sistema probabilístico. Segundo essa visão, a linguagem é padronizada, isto é, muitos traços linguísticos teoricamente possíveis não ocorrem na língua em uso com a mesma frequência (BERBER SARDINHA, 2004). Segundo Berber Sardinha, "um padrão léxico-gramatical é uma sequência recorrente de (pelo menos duas) palavras, dentro de um espaço delimitado (normalmente equivalente a até quatro palavras de distância), que possui um sentido específico" (2009, p.12). Em nossa língua nativa, usamos esses padrões de forma automática, ou seja, não selecionamos palavras isoladas para a construção dos discursos e é esse uso de unidades já padronizadas que nos permite usar a língua com fluência (SINCLAIR, 1991). 
Os padrões lexicogramaticais podem ser formalizados em três conceitos principais, que são: colocação, coligação e prosódia semântica (BERBER SARDINHA, 2004). A colocação é considerada "a tendência de duas palavras de coocorrerem, ou como a tendência de uma palavra atrair outra"6 (HUNSTON, 2002, p.68), ou seja, uma associação de itens lexicais. Segundo Sinclair (1991), a colocação ilustra o princípio idiomático (idiom principle) em contraposição ao princípio de escolha aberta (open-choice), pois "palavras não ocorrem de forma aleatória em um texto"7 (SINCLAIR, 1991, p.110). Um exemplo de colocação é shed tears; alguns outros colocados de shed são: light, jobs e blood (HUNSTON, 2002). A coligação é, segundo Firth, "a inter-relação das categorias sintáticas"8 (PALMER, 1968, p.23), ou seja, está no nível gramatical e concerne à associação entre itens lexicais e gramaticais. Um exemplo bastante claro é o selecionado por Berber Sardinha (2004, p.40): "start é mais comum com sintagmas nominais e orações -ing, enquanto begin é mais usado com um complemento to". A prosódia semântica é a associação entre itens lexicais e conotação (negativa ou positiva) ou instância avaliativa (BERBER SARDINHA, 2004).

\footnotetext{
6 "the tendency of two words to co-occur, or as the tendency of one word to attract another" (HUNSTON, 2002, p.68).

7 "words do not occur at random in a text" (SINCLAIR, 1991, p.110).

8 "the interrelations of the syntactical categories" (PALMER, 1968, p.23).
} 
Um dos exemplos de prosódia semântica mais citados é o dado por Stubbs (1996): a palavra cause tem uma prosódia semântica negativa por coocorrer com palavras de conotação negativa como problem(s), illness, disaster, damage e concern.

As principais áreas de interesse da Linguística de Corpus de acordo com Kennedy (1998) são, de forma sucinta, a compilação e a construção de corpora, o desenvolvimento de ferramentas para análise de corpora, a descrição da linguagem e o ensino-aprendizagem de línguas. Como já apontado, nosso foco é no uso de corpora no ensinoaprendizagem de língua estrangeira, o que detalhamos a seguir.

\subsection{Ensino de Língua Inglesa por meio da Linguística de Corpus}

O interesse de profissionais da área de ensino e aprendizagem de línguas no trabalho com corpora advém do reconhecimento da necessidade de priorizar o ensino de padrões lexicais e de que esses padrões não poderiam ser selecionados apenas pela introspecção (SINCLAIR, 2004b). Esse interesse e o uso de corpora por esses profissionais ocorrem há mais de 20 anos, como podemos ver pelas pesquisas de Sinclair (1987, 1991, 2004a), e tem sido crescente, especialmente pela disponibilidade de programas e ferramentas de fácil utilização e da maior facilidade de 
acesso a corpora, que estão disponíveis online para serem baixados e/ou comprados (RÖMER, 2006, 2009; BERNARDINI, 2004).

Com relação ao uso de corpora em sala de aula de língua estrangeira, Aijmer (2009) afirma que ainda há certa resistência ou falta de habilidade por parte de professores, mas prevê um futuro promissor. Römer (2009) sustenta que os linguistas de corpus têm um trabalho árduo para enfrentar o desafio de professores e alunos que estão acostumados a métodos mais tradicionais e sugere que uma tarefa importante é divulgar a LC e informar os professores sobre o que existe disponível para ajudá-los em sua prática pedagógica, como corpora online, materiais baseados em corpora, materiais de referência sobre corpora, entre outros.

Para Sinclair (2004a) e Tim Johns (1991), em sua proposta de Aprendizado Movido por Dados (Data Driven Learning 99, doravante DDL, o aluno deve ter acesso direto a um corpus e explorar a linguagem respondendo às suas próprias questões e hipóteses, desenvolvendo a habilidade de um pesquisador. Já Aston (1997) afirma que o professor pode simplificar os resultados das buscas no corpus, selecionando e filtrando os textos de acordo com o nível de compreensão do aluno,

9 Aprendizagem movida a dados (Data Driven Learning - DDL) é uma abordagem cuja ênfase é desenvolver no estudante da língua a habilidade de pesquisa e de descoberta, colocando à sua disposição dados de um corpus. 
especialmente no caso de iniciantes. Segundo o autor, "talvez o uso mais óbvio de corpora seja tratá-los como fontes de materiais que o professor pode selecionar e adaptar de acordo com o que for necessário"10 (ASTON, 1997, p.52).

As grandes vantagens do DDL são (BERNARDINI, 2004; BERBER SARDINHA, 2004; O'SULLIVAN, 2007; CHAMBERS, 2010; GILQUIN e GRANGER, 2010):

1) Uso e exploração de linguagem autêntica na sala de aula e grandes quantidades de exemplos, não para a simples repetição (drills), mas sim para o que Ellis (2002, p.177) chama de repetição consciente (mindful repetition), ou seja, a leitura das mesmas instâncias visando ao entendimento dos padrões e itens linguísticos. Esse acesso à linguagem autêntica e a uma quantidade de exemplos maior do que pode ser encontrado em livros de referência usados por alunos e professores, como dicionários, gramáticas e livros didáticos, leva à expansão do vocabulário e à percepção e conscientização de padrões lexicogramaticais.

2) A modificação do papel do professor de "Fonte

10 "perhaps the most obvious pedagogic use of corpora is to treat them as sources of classroom materials which the teacher can select from and adapt according to requirements." (ASTON, 1997, p.52) 
de conhecimento" para facilitador, auxiliando os alunos a interpretar os dados e a fazer suas buscas, com acesso a exemplos de língua em uso. 3) O fato de o aluno desenvolver maior autonomia, independência e responsabilidade sobre sua aprendizagem, além de habilidades como fazer previsões e observações, pensar, notar, analisar, raciocinar, interpretar, deduzir, comparar, entre outras.

4) A possibilidade de 0 aluno corrigir-se comparando seu uso da língua ao uso de nativos ou ótimos usuários (expert) e de refletir sobre as questões da língua; o elemento da descoberta faz a aprendizagem ser mais motivadora e divertida.

Bernardini (2004, p.22), seguindo as premissas do DDL, propõe o DL (Discovery Learning), uma abordagem na qual os alunos "são guiados a observar grandes coletâneas de textos variados de uma maneira aberta e exploratória"11. A autora opta pelo acesso direto dos alunos a corpora; entretanto, diferentemente de Johns (1991), considera que os alunos devam assumir o papel de descobridores, e não de pesquisadores, considerando que os alunos podem

11 "are guided to browse large and varied text collections in open-ended, exploratory ways" (BERNARDINI, 2004, p.22) 
não ter as competências e capacidades que professores e/ou linguistas possuem enquanto pesquisadores. Para a autora, a Aprendizagem como Descoberta (Discovery Learning) incentiva os alunos a seguir seus interesses e desenvolver capacidades de forma que "suas buscas tornemse mais focadas, suas interpretações mais precisas e seu entendimento mais afiado sobre o uso de corpus e sobre a língua"12 (BERNARDINI, 2004, p.23).

Conforme aponta Chambers (2010), não se defende a ideia do DDL como o principal ou único componente no ensino de línguas, mas sim como um recurso para encorajar a observação da língua em uso, a descoberta, a formulação de hipóteses e, consequentemente, a autonomia, não fugindo às principais premissas da abordagem, que são o princípio idiomático da língua e a descoberta de padrões lexicogramaticais, bem como o uso de concordâncias como instrumento para a observação desses padrões. A maneira como o professor irá usar o corpus e as concordâncias irá depender do contexto de aprendizagem, do nível dos alunos, da disponibilidade de materiais, entre outros fatores.

12 "their searches become better focused, their interpretation of results more precise, their understanding of corpus use and their language awareness sharper" (BERNARDINI, 2004, p.23) 


\subsection{Concordâncias na sala de aula}

Como exposto anteriormente, uma das formas de se utilizar textos autênticos e corpora em sala de aula é por meio das concordâncias. Segundo Berber Sardinha (2004)), “a concordância é empregada para exemplificar o uso (usage) de traços linguísticos e as situações nas quais ocorre" (p.273). Usando o programa Wordsmith Tools, de Mike Scott (2008), por exemplo, podemos obter uma listagem das ocorrências de um item selecionado no conteúdo de vários textos ao mesmo tempo. Assim, a palavra estudada fica centralizada na tela e é possível fazer uma leitura hipertextual das palavras que ocorreram junto a ela no corpus. Dessa forma, a palavra está em seu contexto original e o usuário tem acesso a uma porção de texto maior da ocorrência a ser estudada no próprio programa.

Berber Sardinha (2011) lista o que deve ser levado em conta ao preparar atividades baseadas em concordâncias, sendo: (a) escolha da palavra de busca, que é guiada pelos objetivos da atividade, da aula, da unidade e do curso; (b) modo de apresentação, ou seja, se a aula será em um laboratório ou na sala de aula, o que implica na necessidade de o professor trazer a concordância pronta impressa ou para projetar; (c) tipo de concordância: geral (com todas as 
ocorrências), selecionada, editada (sem símbolos ou palavras cortadas, por exemplo), preenchida (com a palavra de busca) ou lacunada (com lacunas no lugar da palavra de busca); (d) quantidade de concordâncias e (e) exercícios, como perguntas, completar frases, ligar colunas, entre outros.

O autor então explica os ingredientes que o professor precisa para preparar a atividade, o corpus e um software para produção de concordâncias e indica que o professor deve ensinar ao aluno como ler uma concordância e como observar os padrões lexicogramaticais. O professor pode selecionar as concordâncias previamente, atentando a questões como número, seleção e simplificação das linhas; outra opção é o aluno produzir as concordâncias, atividade que requer que o professor ensine o aluno a usar o software, formular buscas, selecionar linhas, etc.

Nas atividades centradas no texto, propostas por Berber Sardinha (2011), a concordância está presente, mas assume um papel secundário, visto que o foco é no texto. Nesse tipo de atividade, não há a desvantagem de o aluno sentir falta do contexto ou de uma situação concreta de uso da língua. Dentre suas vantagens, citamos a contextualização dos padrões enfocados e o tempo de preparação que, se feito com o uso do software, é relativamente curto. 


\section{METODOLOGIA DE COLETA E ANÁLISE DOS DADOS}

A compilação do corpus de estudo, denominado ad corpus, foi feita segundo os seguintes critérios levantados por Berber Sardinha (2004): (a) composição, por textos autênticos utilizando linguagem natural, (b) autenticidade, textos produzidos por falantes nativos e em situações reais e (c) seleção criteriosa de acordo com os objetivos da pesquisa.

O ad corpus é composto por 1.118 textos em formato eletrônico e tem 1.004.733 palavras (tokens). Trata-se de um corpus sincrônico de porte médio-grande e que consideramos ser especializado, por ser composto por textos de uma área específica para a exploração da linguagem nela usada. Os textos foram coletados de fonte autêntica, da Internet, de uma revista digital que publica artigos sobre a atuação das agências de Publicidade na área. O site selecionado é o AdAge - Advertising Agency ${ }^{13}$, que fornece informações, notícias e análise de dados sobre marketing e mídia, possibilitando a comunicação para as comunidades de Publicidade e Marketing. A revista teve início em 1930, em formato de jornal e atualmente, em seu formato impresso, é semanal e distribuída em diversos países do mundo, incluindo o Brasil. A revista digital traz publicações em forma de artigos, colunas, vídeos, blogs, podcasts, entre outros.

13 Disponível em http://adage.com. Acesso de julho de 2009 a fevereiro de 2012. 
A escolha por essa fonte para o corpus deve-se a diversos fatores. O primeiro é a questão da disponibilidade e variedade de tipos de textos, de autores e de informações. Em segundo lugar, verificamos que a maior parte dos profissionais da área a consideram uma importante fonte de informações e a utilizam diariamente. Por último, em nossa experiência com aulas nesse contexto, observamos que diversos professores de ILE que trabalham com esses profissionais utilizam essa revista em suas aulas e essa prática é aprovada e até mesmo solicitada pelos próprios alunos, que geralmente desejam ter aulas com temas e linguagem relacionados à área em que atuam. Textos dessa revista e de diversas outras fontes foram comumente utilizados em nossas aulas e, de acordo com os alunos, em conversas informais, a Adage é a mais completa e eles sentiram que o uso dela em sala de aula foi bastante proveitoso para sua aprendizagem do idioma.

Fizemos a seleção dos textos no período de setembro de 2009 a março de 2011 e os textos selecionados datam de maio de 2009 a março de 2011. Selecionamos textos gratuitamente disponíveis e salvos em arquivos do processador de texto Microsoft Word em formato tipo texto sem formatação (.txt). Selecionamos os seguintes textos da revista para a coleta: artigos informativos, denominados 
stories, que contêm notícias sobre a atuação das agências de Publicidade ao redor do mundo, novas campanhas, eventos de premiação, dentre outros temas; artigos informativos e opinativos, chamados de blogs, que apresentam algum tema relacionado à Publicidade juntamente com o comentário e/ou opinião do autor; transcrições de vídeos chamados 3 minutes Adage, que são vídeos de 3 minutos que apresentam algum tema ou campanha realizada por alguma agência de Publicidade. Eles podem ser assistidos no próprio site ou pode ser feito o download (baixar) gratuito por meio do iTunes ${ }^{14}$.

A coleta dos textos foi feita da seguinte forma: com relação aos textos escritos, utilizamos o processo de selecionar, copiar e colar cada texto em um arquivo do Microsoft Word, tanto em formato de documento do Word como em formato texto sem formatação (.txt). Salvamos nos dois formatos para ter a possibilidade de acessar os textos com as imagens e outros itens que são eliminados no formato .txt com mais facilidade. Os vídeos foram assistidos e transcritos por nós e salvos da mesma maneira que os textos escritos. Nomeamos os arquivos da seguinte forma:

14 iTunes é um reprodutor de áudio e vídeo desenvolvido pela Apple, para reproduzir e organizar música digital, arquivos de vídeo e para a compra de arquivos de mídia digital. 
1) Artigos (stories): st_ + numeração. Exemplo: st_0001, st_0002, etc.

2) Artigos opinativos (blogs): bl_ + numeração. Exemplo: bl_0001, bl_0002, etc.

3) Vídeos: vi_ + numeração. Exemplo: vi_0001, vi_0002, etc.

O corpus de referência serve de contraponto ao corpus de estudo, para fins de comparação e de extração de seus padrões lexicogramaticais mais típicos, que emergem a partir do contraste dos dois corpora. Segundo Berber Sardinha (2009, p.226-227), um corpus de referência, também denominado corpus de controle, normalmente possui as seguintes características: (1) é pelo menos 5 vezes maior do que o corpus de estudo; (2) não deve conter o corpus de referência para que não seja feita uma comparação do corpus de estudo com ele mesmo; e (3) deve ser selecionado com um propósito específico para que não sejam comparadas listas de palavras que não tenham relação alguma uma com a outra.

O corpus de referência selecionado foi o British National Corpus, doravante $B N C$, composto por inglês escrito e falado, com cerca de 100 milhões de palavras (tokens). A parte escrita inclui textos de jornais, livros acadêmicos e de ficção, 
cartas, redações, entre outros. A parte falada consiste em transcrições de conversas informais, de idade, regiões e classes sociais diferentes, reuniões governamentais, programas de rádio, entre outros. Essa escolha deveu-se ao fato desse corpus ser referência da Língua Inglesa em uso. Além disso, no momento da pesquisa, era um dos únicos corpora disponíveis gratuitamente para uso em programas computacionais. A lista de palavras apresenta 99.465.296 ocorrências (tokens) e 512.588 itens (types) ${ }^{15}$.

Os corpora foram analisados por meio da ferramenta computacional WordSmith Tools, versão 5.0 (SCOTT, 2008), que oferece meios de analisar corpora em busca da padronização lexicogramatical.

O primeiro passo para a análise foi o uso da ferramenta WordList, que faz uma lista de palavras de um corpus. Ao fazer uma lista de palavras, o programa produz três abas principais: (1) dados estatísticos do corpus (statistics); (2) uma lista de palavras por ordem alfabética (alphabetical); (3) uma lista de palavras por frequência (frequency), que é a que mostramos aqui (Figura 1). Na lista de palavras por frequência, encontramos as seguintes informações: (1) Word: palavra ou item; (2) Freq.: frequência das palavras no corpus

15 Em "Paulo viajou com o seu pai e com o seu irmão", por exemplo, temos 11 ocorrências (tokens) e 8 itens (types). 
de estudo; (4) \%: porcentagem da frequência das palavras considerando a porcentagem do total de ocorrências das palavras; (5) Texts: quantidade de textos nos quais a palavra ocorre; e (6) \%: porcentagem da frequência de ocorrência das palavras nos textos.

O corpus de estudo é constituído de 1.004.733 tokens ou ocorrências, e 32.166 types, que chamamos de itens. A proporção item/ocorrência (Type/Token Ratio) é 3,27. Essa proporção é feita dividindo-se o número de itens pelo número de ocorrências; o resultado é multiplicado por 100 para transformar o valor em porcentagem. Isso significa que quanto maior o valor, mais palavras diferentes e quanto menor o valor, maior o número de repetições; esse valor pode ser interpretado para verificar a riqueza lexical de um texto ou corpus. (BERBER SARDINHA, 2009) ${ }^{16}$.

16 As demais informações apresentadas na janela de estatística não serão aqui abordadas; para explicações detalhadas sobre elas, vide Berber Sardinha (2009). 


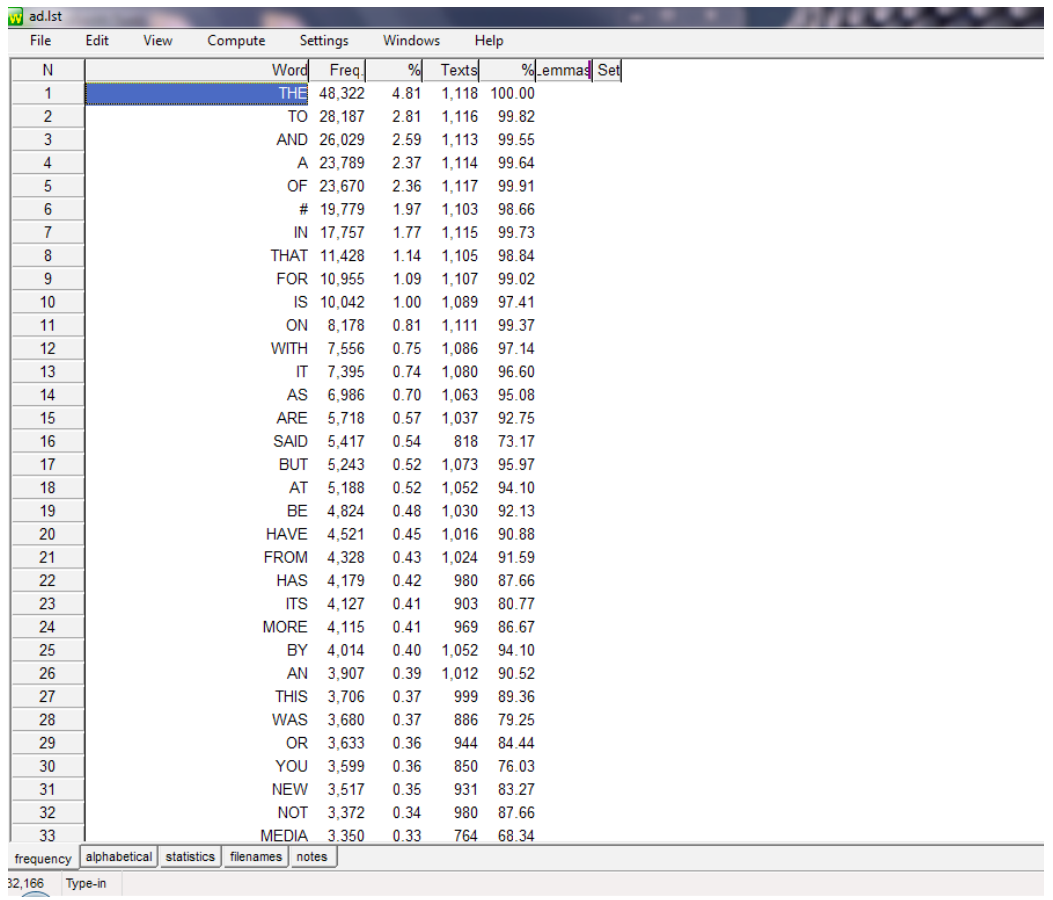

Figura 1: Tela do WordList do Wordsmith Tools com resultado parcial de lista de palavras do corpus de estudo por frequência.

Podemos observar que na lista das palavras mais frequentes do corpus de estudo encontramos artigos, preposições, pronomes e verbos, sendo que o primeiro item relacionado à área de Publicidade, media, está na 33ạ posição. Assim, para a observação e seleção das palavras mais representativas no corpus de estudo, fizemos a comparação entre a lista de palavras dele e a do corpus de referência $(B N C)$. Para tanto, utilizamos a ferramenta Keywords, "que permite a seleção de itens de uma lista de palavras (ou mais) 
por meio da comparação de suas frequências com uma lista de referências" (BERBER SARDINHA, 2004, p.96). A Figura 2 mostra uma janela com uma parte dos resultados.

\begin{tabular}{|c|c|c|c|c|c|c|c|c|c|c|c|}
\hline \multicolumn{12}{|c|}{ KeyWords } \\
\hline File & \multicolumn{2}{|c|}{ Edit } & View & Compute & \multicolumn{2}{|c|}{ Settings } & \multicolumn{2}{|c|}{ Help } & & \multirow[b]{2}{*}{$\mathrm{P}$} & \multirow[b]{2}{*}{ Lemmas } \\
\hline $\mathrm{N}$ & & & & Key wor & & Freq. & $\%$ & RC. Freq- & RC. \%| Keyness & & \\
\hline 1 & & & & $\mathrm{~A}[$ & & 2,987 & 0.30 & 3,078 & $19,175.07$ & 0.0000000000 & \\
\hline 2 & & & & MEDI & & 3,350 & 0.33 & 7,862 & $17,348.14$ & 0.0000000000 & \\
\hline 3 & & & & MARKETINC & & 2,821 & 0.28 & 5,198 & $15,692.8 \mathbf{1}$ & 0.0000000000 & \\
\hline 4 & & & & BRANL & & 2,283 & 0.23 & 2,032 & $15,105.7 d$ & 0.0000000000 & \\
\hline 5 & & & & ARKETERS & & 1,390 & 0.14 & 61 & $12,299.3 q$ & 0.0000000000 & \\
\hline 6 & & & & FACEBOO & & 1,139 & 0.11 & 0 & $10,491.7 \mathrm{~d}$ & 0.0000000000 & \\
\hline 7 & & & & $\mathrm{CON}$ & & 1,212 & 0.12 & 281 & $9,725.86$ & 0.0000000000 & \\
\hline 8 & & & & BRANDS & & 1,355 & 0.13 & 770 & $9,714.46$ & 0.0000000000 & \\
\hline 9 & & & & VERTISINC & & 1,872 & 0.19 & 4,400 & $9,687.03$ & 0.0000000000 & \\
\hline 10 & & & & DNSUMERS & & 1,525 & 0.15 & 2,290 & $8,959.66$ & 0.0000000000 & \\
\hline 11 & & & & ADS & & 1,220 & 0.12 & 599 & $8,944.69$ & 0.0000000000 & \\
\hline 12 & & & & ONLINE & & 1,185 & 0.12 & 597 & $8,654.87$ & 0.0000000000 & \\
\hline 13 & & & & AGENCY & & 1,804 & 0.18 & 5,645 & $8,484.58$ & 0.0000000000 & \\
\hline 14 & & & & GOOGLE & & 905 & 0.09 & 0 & $8,336.11$ & 0.0000000000 & \\
\hline 15 & & & & CEC & & 886 & 0.09 & 93 & $7,548.24$ & 0.0000000000 & \\
\hline 16 & & & & DIGITAI & & 1,279 & 0.13 & 1,915 & $7,519.67$ & 0.0000000000 & \\
\hline 17 & & & & $T$ & & 1,610 & 0.16 & 6,294 & $6,966.77$ & 0.0000000000 & \\
\hline 18 & & & & TWITTEF & & 727 & 0.07 & 11 & $6,582.24$ & 0.0000000000 & \\
\hline 19 & & & & ADAGE & & 692 & 0.07 & 115 & $5,715.39$ & 0.0000000000 & \\
\hline 20 & & & & & U & 1,210 & 0.12 & 4,344 & $5,410.42$ & 0.0000000000 & \\
\hline 21 & & & $\Delta \cap 1$ & VFRTISFR! & & fuA & $\cap \cap \kappa$ & $31 n$ & $\triangle 73498$ & ก กกกกกกกกกก & \\
\hline KWs & plot & links & clusters & filenames & notes & source text & & & & & \\
\hline 1500 & Type & & & & & & & & & & \\
\hline
\end{tabular}

Figura 2: Tela do KeyWords do Wordsmith Tools com resultado parcial de chavicidade (keyness) da comparação entre a lista de palavras do corpus de estudo e da lista de palavras do corpus de referência.

As palavras-chave aparecem em ordem de chavicidade, de forma que no topo da lista estão as positivas, ou seja, as que possuem frequência significativamente mais alta no corpus de estudo do que no de referência. Quando o contrário acontece, as palavras-chave são denominadas negativas.

A partir da lista de palavras-chave, selecionamos as mais frequentes, tendo em mente a transposição dos achados 
para atividades didáticas. A análise das palavras-chave e seus colocados foi feita com a ferramenta Concord do Wordsmith Tools. A Figura 3 mostra a aba Patterns, na qual podemos verificar os colocados de ad, ou seja, as palavras que mais ocorrem juntamente com ad.

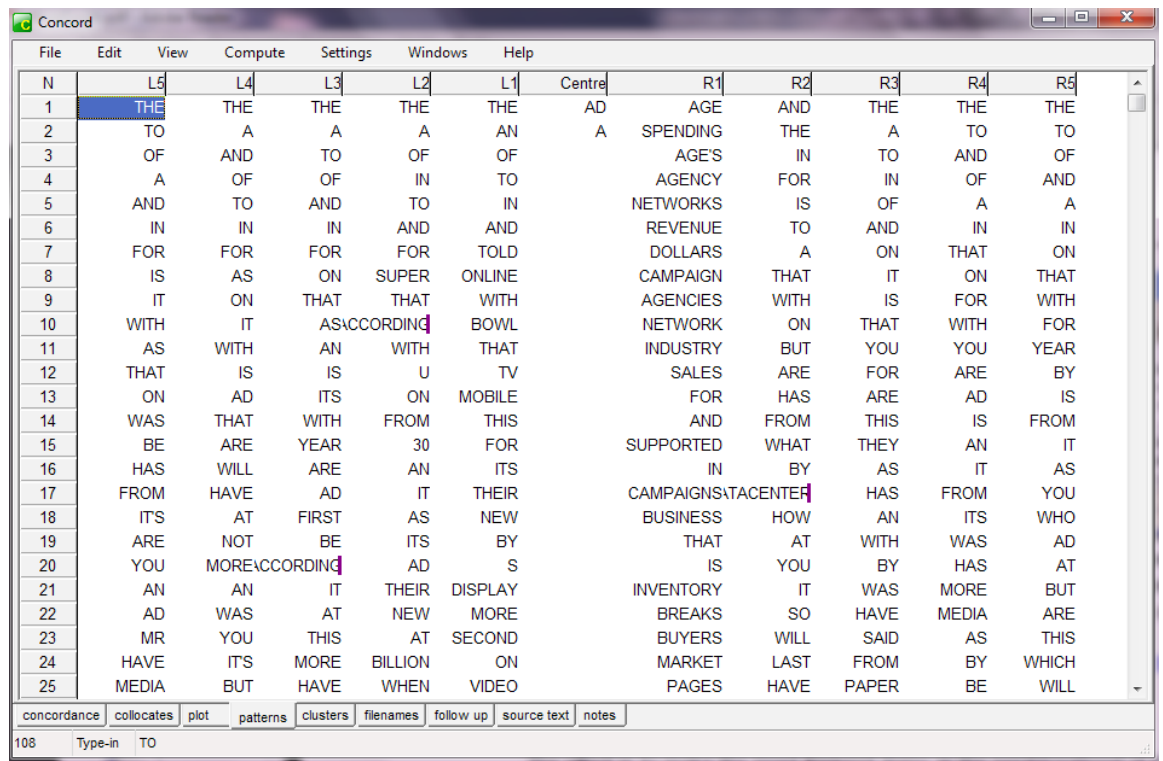

Figura 3: Tela do Concord, aba Patterns, do Wordsmith Tools com os padrões de ad.

Ainda dentro da ferramenta Concord, analisamos os padrões lexicogramaticais típicos com as palavras selecionadas por meio de cálculos estatísticos para medir o grau de associação entre os itens, ou seja, o grau de coocorrência entre um nódulo e seus colocados. Dentre as medidas de associação disponíveis, utilizamos a Informação Mútua (Mutual Information) e o Escore T (T Score). Ambas 
consideram a razão O/E, ou seja, Observado/Esperado, levando em conta, segundo Berber Sardinha (2004, p.201), "quantas vezes de fato duas palavras ocorreram juntas dentro do horizonte delimitado (o valor observado) e quantas vezes seria esperado que elas ocorressem (o valor esperado), dado o tamanho do corpus e a frequência de cada palavra". O Escore T, por sua vez, identifica as associações não tão constantes, porém mais frequentes na língua (BERBER SARDINHA, 2004). Um exemplo do nosso corpus de estudo é ad to. Segundo Berber Sardinha (2004), podemos afirmar, com base nos cálculos de IM, que uma associação entre duas palavras é, de fato, uma colocação, se o resultado for superior a 3. Já no caso do Escore T, uma palavra é considerada colocada de um nódulo quando o resultado for superior a 2. Levando em conta esses cálculos, selecionamos em nossa análise os colocados que tivessem resultado de IM (Informação Mútua) acima de 3 e de Escore T acima de 2.

Observamos na Tabela 1 a seguir as 20 primeiras palavraschave do corpus de estudo em ordem de chavicidade.

\begin{tabular}{|l|l|l|l|l|l|l|}
\cline { 2 - 7 } \multicolumn{1}{c|}{} & Palavra & $\begin{array}{l}\text { Frequência } \\
\text { no corpus de } \\
\text { estudo }\end{array}$ & $\begin{array}{l}\text { \% estatística } \\
\text { da frequência } \\
\text { no corpus de } \\
\text { estudo }\end{array}$ & $\begin{array}{l}\text { Frequência } \\
\text { no corpus de } \\
\text { referência }\end{array}$ & $\begin{array}{l}\text { \% estatística } \\
\text { da frequência } \\
\text { no corpus de } \\
\text { referência }\end{array}$ & $\begin{array}{l}\text { Chavicidade } \\
\text { (log-likelihood) }\end{array}$ \\
\hline 1 & ad & 2.987 & 0,30 & 3.078 & 0,0030945 & $19.175,07$ \\
\hline 2 & media & 3.350 & 0,33 & 7.868 & 0,0079102 & $17.348,12$ \\
\hline 3 & marketing & 2.821 & 0,28 & 5.198 & 0,0052259 & $15.692,83$ \\
\hline 4 & brand & 2.283 & 0,23 & 2.032 & 0,0020392 & $15.105,70$ \\
\hline 5 & marketers & 1.390 & 0,14 & 61 & 0,0000613 & $12,299.38$ \\
\hline 6 & facebook & 1.139 & 0,11 & 0 & 0 & $10.491,78$ \\
\hline
\end{tabular}




\begin{tabular}{|l|l|l|l|l|l|l|}
\hline 7 & com & 1.212 & 0,12 & 281 & 0,0002825 & $9.725,86$ \\
\hline 8 & brands & 1.355 & 0,13 & 770 & 0,0007741 & $9.714,46$ \\
\hline 9 & advertising & 1.872 & 0,19 & 4.400 & 0,0044236 & $9.687,03$ \\
\hline 10 & consumers & 1.525 & 0,15 & 2.290 & 0,0023023 & $8.959,66$ \\
\hline 11 & ads & 1.220 & 0,12 & 599 & 0,0006022 & $8.944,69$ \\
\hline 12 & online & 1.185 & 0,12 & 597 & 0,0006002 & $8.654,87$ \\
\hline 13 & agency & 1.804 & 0,18 & 5.645 & 0,0056753 & $8.484,58$ \\
\hline 14 & google & 905 & 0,09 & 0 & 0 & 8.336 .11 \\
\hline 15 & ceo & 886 & 0,09 & 93 & 0,0000934 & $7.548,24$ \\
\hline 16 & digital & 1.279 & 0,13 & 1.915 & 0,0019252 & $7.519,67$ \\
\hline 17 & tv & 1.610 & 0,16 & 6.294 & 0,0063278 & $6.966,77$ \\
\hline 18 & twitter & 727 & 0,07 & 11 & 0,000011 & $6.582,24$ \\
\hline 19 & adage & 692 & 0,07 & 115 & 0,0001156 & $5.715,39$ \\
\hline 20 & u & 1.210 & 0,12 & 4.344 & 0,0043673 & 5.410 .42 \\
\hline
\end{tabular}

Tabela 1: Resultado da extração de palavras-chave - 25 primeiras em ordem de chavicidade

(keyness).

valor $p$ usado em testes estatísticos varia de 0 a 1.0 valor 01 , por exemplo, indica que existe $1 \%$ de possibilidade de erro em se afirmar a existência de uma relação, ou seja, pode ter ocorrido "por acaso". Todas as palavras da Tabela 1 possuem valor menor do que 0.000001, o que mostra que elas possuem grande significância, visto que a probabilidade de a diferença ter ocorrido por acaso é muito baixa.

A seleção dos itens foi feita de acordo com o nosso objetivo, que foi o de proporcionar o estudo do uso do vocabulário da área de Publicidade. Assim, optamos por eliminar as palavras que nomeiam sites da Internet e redes de relacionamentos, como Facebook, Google e Twitter. Apesar de relevantes para o ensino da língua, preferimos desenvolver, neste trabalho, atividades com palavras mais específicas da área. A palavra "com" no corpus de estudo refere-se, em geral, ao domínio que compõe um endereço da Internet; adage refere-se ao nome da revista e " $u$ " refere-se a "U.S." - Estados Unidos 
(United States) ou "U.K." - Reino Unido (United Kingdom). Em nossa pesquisa, foi feita uma análise mais extensa; no entanto, aqui apresentamos a análise apenas da primeira palavra-chave $(a d)$ e como ela pode ser estudada pelos alunos.

\subsection{Análise de ad}

A palavra-chave selecionada para o desenvolvimento da atividade aqui apresentada foi $a d$, que aparece na primeira posição na lista de palavras-chave quando da comparação do ad corpus com o corpus de referência. Usamos a ferramenta Concord, do Wordsmith Tools para observar seus colocados, conforme mencionado anteriormente (ver Figura 3). Dentre eles, observamos que os que mais ocorrem na posição L1, ou seja, logo à esquerda de ad, são palavras gramaticais, isto é, determinantes e preposições, como the, to, an e of'. À direita, encontramos age com maior frequência, o que pode ser explicado pelo nome da revista (Adage). A seguir, vêm as palavras spending, agency e networks (ver Tabela 2).

Como nossa proposta foi analisar os colocados que apresentam forte associação, optamos por analisar os que tivessem valores de IM altos. Esses colocados não são tão frequentes na língua, mas possuem ocorrência constante; 
consideramos também que eles tivessem Escore T maior do que 2, o que indica que não deixam de ser frequentes.

Dentre esses colocados, encontramos somente uma palavra gramatical, que é an; entendemos que esse resultado corrobora nossa ideia inicial de estudar as palavras de conteúdo, por terem uma relação mais direta com o nódulo. Observando as linhas de concordância, vimos que os colocados selecionados possuem frequência alta na posição R1, à direita do nódulo. Fizemos, portanto, uma busca dos colocados nessa posição e encontramos, dentre as 10 primeiras, em ordem de frequência:

\begin{tabular}{|l|l|l|l|l|l|}
\cline { 2 - 6 } \multicolumn{1}{c|}{} & COLOCADO & $\begin{array}{l}\text { FREQUÉNCIA NO } \\
\text { CORPUS }\end{array}$ & $\begin{array}{l}\text { FREQUẼNCIA } \\
\text { NA POSIÇÃO R1 }\end{array}$ & IM & ESCORE T \\
\hline 1 & age & 553 & 540 & 9,700 & 23,448 \\
\hline 2 & spending & 140 & 130 & 9,422 & 11,815 \\
\hline 3 & Age's & 98 & 95 & 18,135 & 9,899 \\
\hline 4 & agency & 131 & 79 & 9,551 & 11,430 \\
\hline 5 & networks & 106 & 76 & 10,819 & 10,290 \\
\hline 6 & revenue & 100 & 74 & 9,656 & 9,988 \\
\hline 7 & campaign & 76 & 63 & 8,032 & 8,684 \\
\hline 8 & dollars & 67 & 63 & 10,374 & 8,179 \\
\hline 9 & agencies & 67 & 55 & 9,325 & 8,472 \\
\hline 10 & industry & 60 & 49 & 6,655 & 7,699 \\
\hline
\end{tabular}

Tabela 2: Colocados principais de ad com frequência na posição R1.

Encontramos também campaigns, no plural, em 16응 lugar e network, no singular, na 11a posição. Observando novamente as linhas de concordância, pudemos concluir que esses padrões apresentam um sentido específico, sendo, portanto, relevantes para estudo e, consequentemente, para o ensino. O próximo passo foi, então, selecioná-los para uma observação de seu uso. Os padrões ad age, ad age's 
e ad agency estavam, em sua grande maioria, relacionados ao nome da revista, AdAge. Dessa forma, selecionamos os seguintes para a análise: ad spending, ad network(s), ad revenue e ad campaign.

Para analisar o uso desses padrões, utilizamos a ferramenta Concordance, que traz as linhas de concordância e os colocados do item selecionado. Neste artigo apresentamos a análise de ad campaign(s), por esse padrão estar diretamente relacionado com a atividade apresentada. Analisamos os 5 itens que ocorrem com ele com mais frequência e depois discutiremos os que podem ser relevantes para serem ensinados com os padrões.

Com o padrão ad campaign(s), encontramos uma coocorrência de preposições, como se pode ver nas Tabelas 3 e 4.

\begin{tabular}{|l|l|l|l|l|}
\cline { 2 - 5 } \multicolumn{1}{c|}{} & COLOCADO & FREQUENCIA & IM & ESCORE T \\
\hline 1 & the & 27 & 6,793 & 5,149 \\
\hline 2 & an & 22 & 10,657 & 4,688 \\
\hline 3 & a & 20 & 7,833 & 4,453 \\
\hline 4 & of & 10 & 6,349 & 3,123 \\
\hline 5 & new & 10 & 10,965 & 3,161 \\
\hline 6 & with & 10 & 8,558 & 3,154 \\
\hline 7 & to & 10 & 6,580 & 3,129 \\
\hline 8 & from & 9 & 9,037 & 2,994 \\
\hline 9 & and & 8 & 6,244 & 2,791 \\
\hline 10 & that & 8 & 7,563 & 2,813 \\
\hline 11 & in & 7 & 6,483 & 2,616 \\
\hline 12 & for & 6 & 7,404 & 2,435 \\
\hline 13 & by & 5 & 7,920 & 2,227 \\
\hline
\end{tabular}

Tabela 3: colocados principais de ad campaign.

\begin{tabular}{|l|l|l|l|l|}
\cline { 2 - 5 } \multicolumn{1}{c|}{} & COLOCADO & FREQUENCIA & IM & ESCORE T \\
\hline 1 & and & 17 & 7,332 & 4,098 \\
\hline 2 & of & 12 & 6,612 & 3,429 \\
\hline 3 & the & 11 & 5,497 & 3,243 \\
\hline 4 & for & 7 & 7,627 & 2,632 \\
\hline 5 & a & 5 & 5,833 & 2,197 \\
\hline
\end{tabular}

Tabela 4: Colocados principais de ad campaigns. 
Observamos a seguir as linhas de concordância com o nódulo ad campaign(s) e os colocados to, for, from e by:

1 a sweet deal in which LBL will create a new ad campaign to stimulate sales at $50 \%$ off th

2 nized the need for an organized, strategic ad campaign to drive the ongoing demobilizat

3 ng, pricing strategies, retail promotions and ad campaigns to reach consumers effectively

4 the recession, earning itself a new national ad campaign from Publicis' Saatchi \& Saatchi

$5 \mathrm{f}$ course, to the software giant's ongoing ad campaign from agency Crispin Porter \& Bog

6 mployees. Chrysler breaks the "New Day" ad campaign from BBDO. The spots use third

7 Fox somewhat, but he largely credits an ad campaign from Publicis Worldwide, New $Y$

8 y a just-launched umbrella marketing and ad campaign from WPP's Y\&R that includes $S$

9 mployees. Chrysler breaks the "New Day" ad campaign from BBDO. The spots use third

10 rm details about the upcoming national advertising campaign for Via, other than the offi

11 t's not to say there aren't marketing and advertising campaigns for the Beatles' selected $p$

$12 \mathrm{n}$ the course of 2010, Kraft has launched new ad campaigns for 15 of its "power brands,"

13 new standard of the world," and forthcoming ad campaigns for the brand will center on a

14 is year." The cross-platform ad campaign by the Atlanta shop Lawler Ballard Va

15 better known as FARC. An ad campaign by Bogota-based Lowe SSP3 is helping

16 is being promoted with an ad campaign by WPP's Y\&R with a "Heaven on Earth

1700 by the end of the year. An ad campaign by Sancho BBDO highlights that the $s$

Analisamos as linhas de concordância e vimos que o uso de ad campaign(s) com as preposições, to, for e from à direita mostrou-se interessante. O primeiro bloco de linhas de concordância nos mostra o uso de adjetivo + ad campaign 
+ to + verbo. Esse uso refere-se ao propósito da campanha publicitária. Em segundo lugar, verificamos o padrão adjetivo/ nome da campanha + ad campaign + from/by + nome da agência; vemos aqui que esse padrão é usado em geral para referir-se a uma certa campanha e que agência a criou ou desenvolveu. Por último, encontramos ad campaign + for + marca /empresa, relacionando a marca ou empresa para a qual a campanha foi criada ou desenvolvida.

Como podemos observar nas concordâncias, o adjetivo new é um colocado típico à esquerda de ad campaign(s), provavelmente pela natureza dos negócios feitos nas agências, que é a criação de campanhas.

Essas concordâncias nos permitem observar como expandir as ideias relacionadas às campanhas e quais os verbos comumente usados para isso, como use, break e leverage.

Conforme podemos observar nas concordâncias, in é uma preposição que coocorre com ad campaign.

Os padrões que pudemos encontrar com o nódulo estudado são: ad campaign + to / for / from / by, new + ad campaign, in + a/an + (adjetivo) + ad campaign e ad campaign + that. 


\section{DESENVOLVIMENTO DA ATIVIDADE}

Nossa proposta visa desenvolver no aluno a capacidade de observação do vocabulário na língua inglesa em uso em seu meio profissional a fim de detectar os padrões que o envolvem para poder usá-los em sua comunicação. Os alunos também entram em contato com os diversos itens gramaticais apresentados nos livros didáticos de maneira mais livre e significativa, em ocasiões diversas e sem um sequenciamento rígido. Conforme Willis, "considerar o léxico como ponto inicial permite a identificação dos significados e padrões mais comuns e oferece aos alunos uma imagem do que é típico na maneira como o inglês é usado"17 (WILLIS, 1990, p.129), o que, a nosso ver, desperta o interesse dos alunos.

Essa proposta condiz com as abordagens aqui discutidas no que concerne à exposição do aluno a linhas de concordância com questões formuladas pelo professor que irão guiá-lo a encontrar os padrões mais frequentes (JOHNS, 1991; SINCLAIR, 1991; HUNSTON, 2002; BERNARDINI, 2004; BERBER SARDINHA, 2004, 2009, 2011). Concordamos com a ideia de Bernardini (2004) ao tratar o aluno como um descobridor e não como pesquisador, como sugere Johns

17 "taking lexis as a starting point enables us to identify the commonest meanings and patterns and to offer students a picture which is typical of the way English is used" (WILLIS, 1990, p.129) 
(1991); entretanto, usamos como base a análise da linguagem por meio de concordâncias, premissa do DDL.

De acordo com as propostas de ensino de ILE baseado em corpora, elencamos os seguintes pressupostos para o desenvolvimento de nossa atividade:

1) Uso de textos autênticos, não criados com um propósito pedagógico, mas sim para uma comunicação real;

2) Criação de oportunidades para os alunos usarem a língua para comunicação real;

3) Uso de linhas de concordância para a exploração da língua em uso;

4) Foco na lexicogramática, nos padrões lexicogramaticais e nas colocações;

5) Desenvolvimento das habilidades de exploração e descoberta dos alunos;

6) Papel do professor de observador, mediador e facilitador, guiando os alunos para as descobertas.

Procuramos desenvolver uma atividade em que os alunos pudessem lidar com o texto e com o corpus, pois acreditamos que "texto e corpus são duas unidades de língua que se completam naturalmente, até porque a segunda 
é uma coletânea da primeira" (BERBER SARDINHA, 2009). Conforme explica o autor, um corpus pode ser interessante, porém não pode ser lido de forma linear como um texto, mas sim convida a uma leitura hipertextual; um corpus explicita a intertextualidade, enquanto o texto a supõe. A leitura e discussão dos textos da área são importantes para que os alunos possam comunicar-se sobre assuntos de sua realidade, o que, em nossa experiência, mostrou-se ser um fator de motivação.

Observa-se que é possível desenvolver a atividade com ferramentas e recursos variados, de forma que o professor pode preparar os exemplos previamente, se não tiver os recursos em sala de aula, assim como usá-los juntamente com os alunos, se houver a possibilidade. O tempo da atividade varia de acordo a disponibilidade de um computador em sala de aula ou não, com o número de alunos e seu rendimento, entre outros fatores. A princípio, no entanto, calculamos que ela possa ser realizada em 2 aulas de 1 hora e trinta minutos cada, lembrando que esse tempo depende do contexto de ensino, do rendimento dos alunos, dos recursos disponíveis para o professor em sala de aula, entre outros fatores.

Cabe ressaltar que essa proposta pode ser usada em aulas individuais ou em grupos. No caso de aulas individuais, 
os alunos podem refletir sozinhos e reportar suas ideias ao professor ou então discutir as questões juntamente com ele, que terá um papel de participante da discussão, e depois reportar a discussão por escrito, em forma de redação, por exemplo. Além disso, sugerimos em alguns momentos que o aluno busque mais exemplos em linhas de concordância do item que está estudando. Isso pode ser feito pelo professor antecipadamente, de forma impressa, ou, se houver a possibilidade, com o uso de um ou mais computadores em sala de aula.

A atividade aqui apresentada parte de um padrão a ser explorado, que é o ad campaign. Desenvolvemos a atividade utilizando o corpus de estudo e uma das ferramentas do programa $A n t C_{0} c^{18}$, por ser de mais fácil uso, de acordo com pareceres de professores que já utilizaram o Wordsmith Tools e o AntConc. Sugerimos também que o professor explore o uso dos padrões usando o COCA (Corpus of Contemporary American English), mencionado no exercício (1). Da mesma maneira, é possível preparar as linhas de concordância previamente e utilizá-las em sala de aula em formato impresso. A atividade é apresentada em formato de slides do programa Microsoft PowerPoint.

A princípio, sugerimos que os alunos reflitam e discutam

18 http://www.antlab.sci.waseda.ac.jp/software.html 
sobre uma campanha publicitária (ad campaign). A primeira parte da atividade traz linhas de concordância para o estudo do padrão e seus colocados. Os alunos observam as linhas do corpus de estudo e associam os usos aos propósitos (Ver Figuras 4, 5 e 6).

\section{ACTIVITY - PATTERN: AD/ADVERTISING CAMPAIGN}

1) Think about everything that involves an ad campaign:

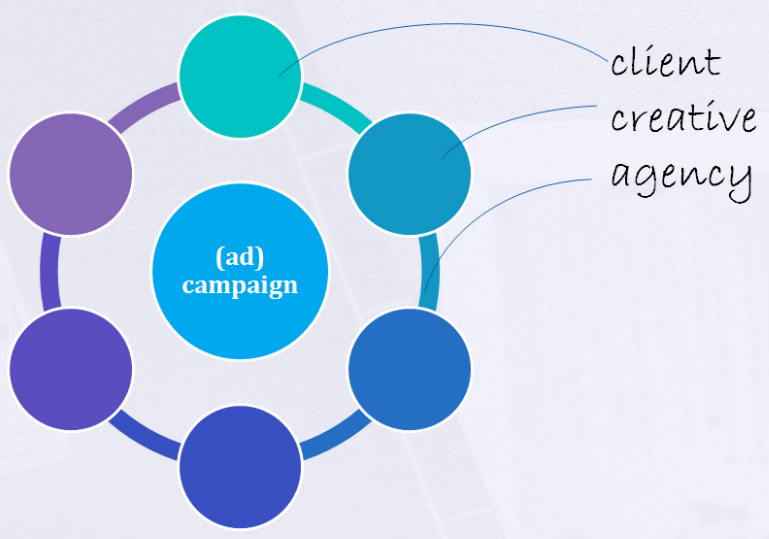

Figura 4: Slide $1 \mathrm{da}$ atividade. 
2) Look at the right of 'ad campaign' and mark:

$a \rightarrow$ for the ones that are about the agency (that created the campaign)

$b \rightarrow$ for the ones that are about the product / brand

$c \rightarrow$ for the ones that are about the purpose of the campaign

( ) athan Fox somewhat, but he largely credits an ad campaign from Publicis Worldwide, New York, th

( ) 75 employees. Chrysler breaks the "New Day" ad campaign from BBDO. The spots use third-party

( ) or a sweet deal in which LBL will create a new ad campaign to stimulate sales at $50 \%$ off their nor

( )sen, CMO of the clinic, which started a national ad campaign earlier this year from Adworks, Washi

( ) cognized the need for an organized, strategic ad campaign to drive the ongoing demobilization eff

( ) new standard of the world," and forthcoming ad campaigns for the brand will center on a theme

( ) $\mathrm{h}$ new storytelling techniques and high-impact ad campaigns like the great ads for Apple. But ev

( )rs to attend "the unveiling of its first global advertising campaign" from TBWA/Chiat/Day tomo

( ) nfirm details about the upcoming national advertising campaign for Via, other than the offi

( ) at's not to say there aren't marketing and advertising campaigns for the Beatles' selected $p$

2) Underline the words that common to each one. What pattern can you see?
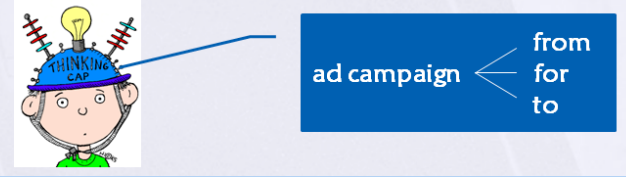

Figura 5: Slide 2 da atividade.

3) Read the excerpts below and identify:

- which / what kind of ad campaign they are about;

- in which ones you know about the company or agency involved in the campaign.

a) Several years ago, the Syracuse University football team did an ad campaign in New York City...

b) "The Beatles: Rock Band, " for instance, launched last week with an estimated \$20 million ad campaign...

c) Sergio Jaramillo, Colombia's vice minister for defense, recognized the need for an organized, strategic ad campaign to drive the ongoing demobilization effort...

d) ...LBL will create a new ad campaign to stimulate sales at $50 \%$ off their normal sticker price for creative services.

e) Chrysler breaks the "New Day" ad campaign from BBDO.

f) It was a nod, of course, to the software giant's ongoing ad campaign from agency Crispin Porter \& Boguksy.

g) The company wouldn't confirm details about the upcoming national advertising campaign for Via...

h) New York-based journalists have gotten invites from the French tire maker and awarder of restaurant stars to attend "the unveiling of its first global advertising campaign" from TBWA/Chiat/Day tomorrow...

Figura 6: Slide 3 da atividade. 
Em seguida, sugerimos que os alunos pesquisem no COCA as palavras que coocorrem com o padrão, comparando esse uso com o uso encontrado no corpus de estudo (Ver Figura 7). Conforme explicamos, os alunos podem conhecer o padrão, mas geralmente encontram dificuldades ou limitações quanto ao seu uso; com esse exercício, eles terão a possibilidade de expandir seu conhecimento e utilizar outros ou colocados frequentemente empregados com ele.

Para realizar um exercício com um texto com mais exemplos do padrão, selecionamos um texto do corpus de estudo por meio da ferramenta Concordance Plot do programa AntConc (Ver Figura 8). Selecionado o texto, desenvolvemos um exercício em que retiramos algumas palavras que coocorrem com ad campaign para que os alunos as reposicionem no texto, como uma tarefa de preencher lacunas (Ver Figura 9). 
3) Do some research on the corpus collected or on COCA (Corpus of Contemporary American English) and find more instances of:

- what collocates with ad campaign

- verbs that collocate with ad campaign(s)

- adjectives that collocate with ad campaign(s)

\begin{tabular}{|c|c|l|}
\multicolumn{3}{c}{ COCA $*+$ ad campaign * } \\
& $\square$ & CONTEXT \\
\hline 1 & $\square$ & AN AD CAMPAIGN \\
\hline 2 & $\square$ & NEW AD CAMPAIGN \\
\hline 3 & $\square$ & THE AD CAMPAIGN \\
\hline 4 & $\square$ & MILLION AD CAMPAIGN \\
\hline 5 & $\square$ & "AD CAMPAIGN \\
\hline 6 & $\square$ & 'S AD CAMPAIGN \\
\hline 7 & $\square$ & TELEVISION AD CAMPAIGN \\
\hline
\end{tabular}

\begin{tabular}{|c|c|l|}
\hline \multicolumn{3}{l|}{ COCA - verb + an ad campaign } \\
\hline 1 & $\square$ & CONTEXT \\
\hline 2 & $\square$ & LAUNCHED AN AD CAMPAIGN \\
\hline 3 & $\square$ & DEVELOPING AN AD CAMPAIGN \\
\hline 4 & $\square$ & DESIGNING AN AD CAMPAIGN \\
\hline 5 & $\square$ & DESIGNED AN AD CAMPAIGN \\
\hline 6 & $\square$ & LAUNCHING AN AD CAMPAIGN \\
\hline 7 & $\square$ & BEGAN AN AD CAMPAIGN \\
\hline & - & \\
\hline
\end{tabular}

http://corpus.byu.edu/coca/

4) Are these collocations similar or different from the ones found in the Advertising corpus?

Figura 7: Slide 4 da atividade.

\section{FURTHERPRACTICE WITHATEXT}

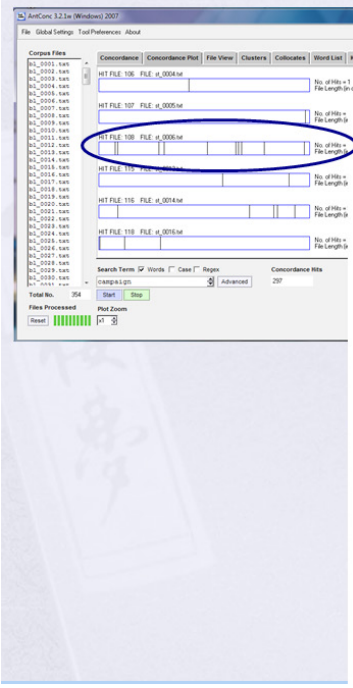

\section{Finding a text for further practice using the corpus collected and AntConc (Concordance plot)}

Figura 8: Slide 5 da atividade - Exemplo de como encontrar um texto que contenha as palavras ou padrões para desenvolver a atividade usando a ferramenta Concordance Plot do programa AntConc. 


\section{FURTHERPRACTICE WITH ATEXT}

5) Read the first part of the text below and decide in which of the black spaces the following words fit:

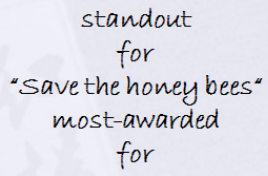

6) Talk about:

- the campaigns mentioned in the text;

- ongoing / forthcoming campaigns.

By: Kunur Patel
The Creativity Awards Report

Goodby, Silverstein \& Partners Tops Agency Winners, While BBDO Remains the MostAwarded Ad Network

Published: September 28, 2009

If Like Tweet $0 \quad \overline{+1} 0$ [+] Share | Email | Reprints | Print I \&

Every year, once the gold dust has settled, Ad Age's Creativity combs through the results of the leading global ad awards to determine which people, companies and campaigns claimed the most hardware.

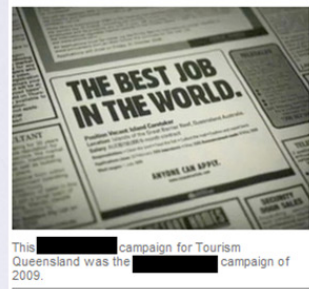

This year, top agencies earned distinction largely due to interactive work. But it's not just interactive know-how that sets an agency apart to awards juries. The most-awarded agency of 2009 is Goodby 2 . Silverstein \& Partners, a shop that simultaneously was named Cannes' digital agency of the year and, according to our count, had the most-awarded TV spot this season with "Rabbit" for Comcast.

What's more, the San Francisco-based Omnicom agency didn't earn this distinction for hitting one home run that won everything - last year's top winners could chalk success up to campaigns like HBO's "Voyeur" and "Halo 3." A broad range of award-winning work and strength across media proved fruitful for Goodby, which won for work such as the http://adage.com/article/agency-news/creativity-awards-report-2009/139270/

Figura 9: Slide 6 da atividade. 


\section{CONSIDERAÇÕES FINAIS}

Nossa prática de ensino nos permitiu verificar as necessidades dos alunos que atuam na área de Publicidade na aprendizagem de ILE. Observamos que os alunos possuíam conhecimento do vocabulário do meio, mas apresentavam dificuldades em utilizá-lo. Devido à falta de materiais didáticos voltados para esse público, que possibilitam aos alunos o contato com a linguagem da área, professores optam por criar suas próprias atividades com textos retirados da Internet; entretanto, essas atividades comumente focam primordialmente questões gramaticais e de vocabulário separadamente, o que não auxilia o aluno a entender o funcionamento da língua em uso. Com a LC, que vê a padronização da língua e considera a lexicogramática, professores e alunos podem enxergar as relações entre os itens da língua, ou seja, as palavras frequentemente usadas com o vocabulário da área, formando padrões que auxiliam os alunos a comunicar-se com mais fluência (SINCLAIR, 1991).

Neste artigo mostramos o desenvolvimento de uma atividade para o ensino de ILE com base no estudo dos padrões lexicogramaticais distintivos do ad corpus, um corpus compilado com o objetivo de servir para a pesquisa dos padrões distintivos da área de Publicidade. Encontramos 
diversos padrões com as palavras-chave resultantes da comparação entre o ad corpus e o BNC, que usamos como corpus de referência. Pudemos analisar os diversos padrões colocados em nossa trajetória; por motivos de espaço, apresentamos a análise dos padrões com o nódulo ad e ad campaign.

Selecionamos alguns dos padrões encontrados para mostrar o desenvolvimento da atividade proposta não seguindo somente uma abordagem de ensino, mas envolvendo diversos pressupostos, de diferentes abordagens de ensino em geral e de ensino com corpora, como o DDL (JOHNS, 1991), Lexical Syllabus (WILLIS, 1990) e as propostas de Berber Sardinha (2009; 2011) de atividades centradas na concordância e no texto.

Com o uso da LC em sala de aula, objetivamos levar o aluno à reflexão sobre a linguagem e ao uso da língua com eficiência, dando-lhe voz, de forma que o ensino possa partir de seus questionamentos sobre esse uso da língua e o professor possa agir como um guia e facilitador, ajudando-o a encontrar suas respostas e customizando o ensino às suas necessidades. Acreditamos, assim, que esta proposta poderá servir de incentivo para que professores possam mudar seus paradigmas, questionar e refletir sobre suas práticas, 
livrando-se da resistência ao novo e do conformismo (CELANI, 1998).

Segundo Moita Lopes, muitas pesquisas em Linguística Aplicada estão "orientadas para a sala de aula" e não "na sala de aula" (2002, p.86 - grifo meu), ou seja, o pesquisador e os envolvidos no processo, professores e alunos, estão distantes entre si. No entanto, o autor aponta para uma tendência de pesquisa, que procuramos fazer, relacionada ao movimento do professor-pesquisador, a pesquisa-ação, na qual o pesquisador está envolvido diretamente com a investigação crítica de sua prática.

Essa é uma das questões mais discutidas hoje com relação ao ensino de LC com corpora. Conforme O'Keefe et al. (2007, p.246), para que a LC possa "informar" para o ensino, professores precisam "informar" à LC, visto que os professores são os melhores mediadores entre as descobertas com corpora e a prática. Os autores fazem algumas sugestões para ajudar professores a sentirem-se confortáveis em usar corpora no ensino, sendo elas maior disponibilidade de corpora e ferramentas online e uma maior diversidade de corpora. Mostramos aqui algumas ferramentas e corpora disponíveis e como o professor pode compilar um corpus e analisar o uso da língua, transpondo seus achados para atividades de ensino. 
Uma das limitações desse trabalho corresponde à compilação do corpus, que pode ser trabalhosa e demandar tempo. A análise e seleção dos itens lexicogramaticais requer certa prática e a mudança da visão da língua como estruturas a serem preenchidas com o léxico para a lexicogramática. 0 desenvolvimento das atividades também demanda tempo e criatividade para que as atividades sejam variadas e compreendam assuntos variados e interessantes ao aluno. Esses são alguns dos "contras" assinalados por Berber Sardinha (2011) e por professores e pesquisadores que usam a LC no ensino em conversas informais. Acreditamos, no entanto, que quando o professor adquire certa prática, a preparação de aulas e de atividades com corpora torna-se menos trabalhosa e é feita em menos tempo, visto que o professor pode reutilizar algumas estruturas de atividades, somente modificando o texto. Em nossa opinião, esse trabalho compensa, pois não é mais possível conceber o ensino da língua sem considerar seu uso e os padrões lexicogramaticais que a envolvem; as descobertas que diversos pesquisadores já fizeram e fazem e que nós estamos começando a fazer são inestimáveis. Acreditamos que ensinar o idioma dessa maneira traz mudanças importantes para os alunos, tanto com relação à visão da linguagem no que diz respeito à padronização, quanto ao desenvolvimento de habilidades 
e capacidades de uso de tecnologias, de manipulação de dados, de descoberta, reflexão e conclusões.

Infelizmente, em nosso país ainda são poucas e limitadas as propostas de LC para o ensino de ILE (BERBER SARDINHA, 2004). Se por um lado podemos tirar proveito do que já foi feito, por outro essa situação abre-nos a oportunidade de ir à busca da construção de novos conhecimentos. Por esses motivos e pela realidade com a qual nos deparamos em sala de aula é que nos propomos a desenvolver esta pesquisa e que apresentamos parte dela no presente artigo.

\section{REFERÊNCIAS}

AIJMER, Karin (2009). "Introduction". In AIJMER, Karin (Ed.). Corpora and language teaching. Amsterdam and Philadelphia: John Benjamins.

ASTON, Guy (1997). "Enriching the learning environment: corpora in ELT". In: WICHMANN, Anne; et al. Teaching and language corpora. London/New York: Longman.

BERBER SARDINHA, Tony (2004). Linguística de Corpus. São Paulo: Manole.

(2006). "Preparação de material didático para Aprendizagem Baseada em Tarefas com Wordsmith Tools e corpora". Calidoscópio, 4(3), 148-155. In www.unisinos.br/publicacoes_cientificas/images/stories/ pdfs_calidoscopio/vol4n3/art03_berber.pdf. Acesso em Mai.2008.

(2007). Corpus linguistics: readings in a widening discipline. DELTA [online], 23 (1), 127-137. In http://www.scielo.br/scielo.php?script=sci_art text\&pid=S0102-44502007000100006. Acesso em Jul.2009.

(2009). Pesquisa em Linguística de Corpus com Wordsmith Tools.

Campinas: Mercado de Letras.

(2011). "Como usar a Linguística de Corpus no ensino de língua 
estrangeira. Por uma Linguística de Corpus educacional brasileira". In: VIANA, Vander.; TAGNIN, Stella. Corpora no ensino de línguas estrangeiras. São Paulo: Hub Editorial. ; ALMEIDA, Gladis Maria de Barcellos (2008). "A Linguística de Corpus no Brasil". In: Tagnin, Stella Esther Ortweiler; Vale, Oto Araujo (Orgs.). Avanços da Linguística de Corpus no Brasil. São Paulo: Humanitas. BERNARDINI, Silvia (2004). "Corpora in the classroom: an overview and some reflections on future developments". In: SINCLAIR, John (Ed.) How to use corpora in language teaching. Amsterdam and Philadelphia: Routledge.

BROWN, H. Douglas (2007). Teaching by principles: an interactive approach to language pedagogy. NY: Pearson.

CELANI, Maria Antonieta (1998). "Transdisciplinaridade na Linguística Aplicada no Brasil". In: SIGNORINI, Inês; CAVALCANTI, Marilda (Orgs.). Linguística Aplicada e Transdisciplinaridade. Campinas: Mercado de Letras.

CHAMBERS, Angela (2005). "Integrating Corpus Consultation in Language Studies". Language Learning and Technology, 9 (2), 111-125.

(2010). "What is data-driven learning?" In: MCARTHY, Michael e O'KEEFE, Anne (Eds.) The Routledge handbook of Corpus Linguistics. New York: Routledge.

CHENG, Winnie (2010). "What can a corpus tell us about language teaching?" In: MCARTHY, Martin e O'KEEFE, Anne (Eds.) The Routledge handbook of Corpus Linguistics. London e New York: Routledge.

; WARREN, Martin; XU, Xun-feng (2003). "The Language Learner as Language Researcher: Corpus Linguistics on the Timetable", System, 31 (2), 173-186.

ELLIS, Nick (2002). "Frequency Effects in Language Processing. A Review with Implications for Theories of Implicit and Explicit Language Acquisition". Studies in Second Language Acquisition, 24, 143-188.

FIRTH, John Rupert (1957) Papers in linguistics - 1934-1951. Oxford: Oxford University Press. 
GAVIOLI, Laura; ASTON, Guy (2001). “Enriching Reality: Language Corpora in Language Pedagogy". ELT Journal, 55 (3) 238-246.

GILQUIN, Gaëtanelle; GRANGER, Sylviane (2010) "How can data-driven learning be used in language teaching?" In MCARTHY, Martin; O'KEEFE, Anne (Eds.). The Routledge handbook of Corpus Linguistics. London e New York: Routledge.

HALLIDAY, Michael Alexander Kirkwood (1994). An Introduction to Functional Grammar. 2.ed. London: Edward Arnold.

HUNSTON, Susan (2002) Corpora in Applied Linguistics. Cambridge: Cambridge University Press.

(1991). "Should you be persuaded: two examples of data-driven learning". ELT Journal. Birmingham: University of Birmingham. 4, 1-16.

KENNEDY, Graeme (1998) An introduction to corpus linguistics. New York: Longman.

MCENERY, Tony e WILSON, Andrew (1997). "Teaching and language corpora". ReCall, 9 (1), 5-14.

MOITA LOPES, Luiz Paulo da (2002). Oficina de Lingüística aplicada - A natureza social e educacional dos processos de ensino-aprendizagem de línguas. Campinas: Mercado de Letras.

O'KEEFE, Anne; McCARTHY, Martin; CARTER, Ronald (2007). From corpus to classroom. Cambridge: Cambridge University Press.

O’SULLIVAN, Íde (2007). “Enhancing a Process-Oriented Approach to Literacy and Language Learning: The Role of Corpus Consultation Literacy". ReCALL, 19 (3), 269-86.

PALMER, Firth Rupert (Ed.) (1968). Selected Papers of J.R. Firth 1952-1959. Longman.

RÖMER, Ute (2006). "Pedagogical applications of corpora: Some reflections on the current scope and a wish list for future developments". Zeitschrift für Anglistik und Amerikanistik, 54 (2), 121-134.

(2009). "Corpus research and practice: what help do teachers need and what can we offer?" In AIJMER, Karin (Ed.). Corpora and 
language teaching. Amsterdam and Philadelphia: John Benjamins. SCOTT, Mike (2008). WordSmith Tools version 5. Liverpool: Lexical Analysis Software.

SINCLAIR, John et al. (1987). Cobuild English Dictionary. London and Birmingham: Collins COBLUID.

(1991). Corpus, Concordance, Collocation. Oxford: Oxford University Press.

(2004a). Trust the text: Language, corpus and discourse. London and New York: Routledge.

(2004b). "Introduction". In: SINCLAIR, John (Ed.) How to use corpora in language teaching. Amsterdam and Philadelphia: Routledge.

STUBBS, Michael (1996). Text and corpus analysis: computer-assisted studies of language and culture. Oxford: Blackwell.

WIDDOWSON, Henry George (1991). "The description and prescription of language". In: ALATIS, James (Orgs.) Georgetown University Round Table on Languages and Linguistics. Washington, D. C.: Georgetown University Press.

WILLIS, Dave (1990). The Lexical Syllabus. London: Collins ELT. ; WILLIS, Jane (2007). Doing Task-based Teaching. Oxford: Oxford University Press.

Cristina Mayer Acunzo é Doutoranda em Linguística Aplicada e Estudos da Linguagem na Pontifícia Universidade Católica de São Paulo - PUC-SP, Mestre em Linguística Aplicada e Estudos da Linguagem pela Pontifícia Universidade Católica de São Paulo - PUC-SP. PUC-SP. CAPES. Berber Sardinha, T., Kauffmann, C., \& Acunzo, C. M. A multdimensional analysis of register variation in Brazilian Portuguese. Corpora, 9(2), 239-271, 2014. GELC - Grupo de Estudos em Linguística de Corpus. cristinaacunzo@ hotmail.com. 